\title{
Postnatal changes in cardiac output and haemorrheology in normal neonates born at full term
}

\author{
Verena H A Mandelbaum, Dale C Alverson, Annette Kirchgessner, Otwin Linderkamp
}

\begin{abstract}
Circulatory adaptation was studied serially in 11 healthy term neonates on days 1,3 , and 5 by cross sectional and pulsed Doppler echocardiography. Changes in the determinants of blood viscosity (packed cell volume, plasma viscosity, red cell aggregation, and red cell deformability) were studied on day 1 and day 5. There was a $27 \%$ increase in the cardiac output as a result of increasing stroke volume, whereas heart rate did not change significantly. Mean blood pressure increased by nearly the same extent as cardiac output (21\%), so that the overall resistance remained unchanged. Packed cell volume, red cell aggregation, and red cell deformability did not change significantly during the first five postnatal days. Plasma viscosity rose significantly (by $12 \%$ ) so that whole blood viscosity increased during that period. As there was no change in overall systemic vascular resistance the vascular hindrance-calculated as the ratio of resistance: blood viscositydecreased, thereby indicating vasodilation.
\end{abstract}

Blood flow in circular vessels is determined by Poiseuille's law with the Hagenbach extension. This means that blood flow $(Q)$ increases with increasing pressure gradient (that is, pressure drop divided by vessel length, $\sigma \mathrm{P} / \mathrm{L}$ ) and increasing vessel radius ( $r$ ), and decreases with increasing blood viscosity $(\eta)$ :

$$
\mathrm{Q}=\frac{\pi}{8} \times \frac{\sigma \mathrm{P}}{\mathrm{L}} \times \frac{\mathrm{r}^{4}}{\eta}
$$

By applying this simplified model to the entire vascular system, it can be calculated that cardiac output increases as arterial blood pressure and generalised vasodilation increase, and decreases as blood viscosity increases. This model may also be used to calculate the resistance to blood flow $(R)$ as a ratio of arterial blood pressure and cardiac output:

$$
R=\frac{P}{Q}=\frac{8}{\pi} \times \frac{L}{r^{4}} \times \eta
$$

$\mathrm{L} / \mathrm{r}^{4}$ expresses the effect of the vessel geometry on the flow resistance ('vascular hindrance', Z). This term was introduced by Lamport $^{1} ; \eta$ represents the effect of blood properties on flow resistance:

$$
\mathbf{R}=\frac{\mathbf{P}}{\mathbf{Q}}=\mathbf{Z} \times \boldsymbol{\eta}
$$

As $P, Q$ and $\eta$ can be measured, $Z$ can be estimated from these variables:

$$
\mathrm{Z}=\frac{\mathrm{P}}{\mathrm{Q} \times \boldsymbol{\eta}}=\frac{\mathrm{R}}{\eta}
$$

In healthy full term neohates, systolic blood pressure increases by an average of $2 \mathrm{~mm} \mathrm{Hg} /$ day during the first five days after birth. ${ }^{2}$ Serial studies of cardiac output during the first postnatal days, however, have given conflicting results. Mahoney et al found a decrease in peak Doppler flow velocity in the aorta during the first three days after birth. ${ }^{3}$ Alverson et al and Arcilla et al found little change in cardiac output during the first five postnatal days, although their studies were not designed to examine this defined time period. ${ }^{45}$ In lambs, cardiac output/kg body weight decreases from birth to 4 weeks of age. ${ }^{67}$ The decrease between week one and week two seems to be the result of an appreciable increase in body weight. The decrease in cardiac output was also associated with an appreciable fall in oxygen consumption. In piglets cardiac output was found to rise with age. ${ }^{8}$ In foals cardiac index increases considerably during the first two weeks as a result of increasing stroke volume and decreasing vascular resistance. ${ }^{9}$

The present study was designed to measure cardiac output, arterial blood pressure, and determinants of blood viscosity in healthy full term neonates during the first five postnatal days.

\section{Subjects and methods NEONATES}

A total of 11 healthy neonates of gestational ages ranging from 38 to 41 weeks (median 40) and birth weights ranging from 2700 to $4350 \mathrm{~g}$ (median 3300) were studied after permission had been obtained from the human subject research committee of the University Hospital Centre of Heidelberg. All the infants were delivered vaginally after uneventful pregnancies. Cords were clamped 10 to 20 seconds after birth. Informed consent was obtained from the parents in each case.

\section{CARDIOVASCULAR VARIABLES}

Cardiac output and blood pressure were measured on the first day of life (at between 2 and 11 hours) and on days 3 and 5. During the examination, which was made at least an hour after the last feed, infants were either sleeping or quiet. None of the infants had received drugs or intravenous fluids. Infants were examined 
lying supine under radiant heaters to maintain a core temperature of $37^{\circ} \mathrm{C}$.

Cardiac output was measured using pulsed Doppler ultrasound as previously described. ${ }^{10}$ The flow velocity integral of the maximal velocity in the ascending aorta was measured from the apical position.

The cross sectional aortic area was calculated from the $M$ mode echocardiogram by the leading edge to leading edge method using a standard parasternal approach. Cardiac output was calculated from the equation cardiac ouput $=$ cross sectional aortic area $\left(\mathrm{cm}^{2}\right)$ multiplied by flow velocity integral $(\mathrm{cm})$ multiplied by heart rate/minute. Length of the evaluated heart beats was measured by computer, so heart rate could be calculated. Examination time for cardiac output measurements averaged 10 minutes. All measurements were done by one investigator (VM). Intraobserver variability for cardiac output determination was $14 \%$.

Blood pressure was measured by a Doppler device (Arteriosonde, Kontron-Roche). Mean blood pressure was calculated as: mean systolic blood pressure plus twice the mean diastolic blood pressure divided by three. Flow resistance was calculated as pressure:flow ratio. Vascular hindrance was calculated as the ratio of flow resistance:blood viscosity.

\section{BLOOD SAMPLES}

Two blood samples were studied from all 11 neonates. Placental blood $(5 \mathrm{ml})$ was taken from the umbilical cord immediately after cord clamping and before delivery of the placenta. The second blood sample $(2 \mathrm{ml})$ was collected by venepuncture on day five. The blood was anticoagulated with $1 \mathrm{mg} / \mathrm{ml}$ EDTA. The second blood sample was also used for the routine screening tests.

\section{GENERAL HAEMATOLOGICAL VARIABLES}

Packed cell volume was measured in duplicate by the microhaematocrit method. The values were not corrected for trapped plasma, which is about $2 \%$ in full term neonates and adults. ${ }^{11}$ Red blood cell count and haemoglobin concentrations were measured with a cell counter (Contraves). Total plasma protein concentration was measured by the biuret test. Plasma fibrinogen, IgM, and $\alpha_{2}$-macroglobulin concentrations were measured by a radioimmunodiffusion technique (M-Partigen kits, Behring).

\section{HAEMORRHEOLOGICAL VARIABLES}

All haemorrheological measurements were made at $22^{\circ} \mathrm{C}$ within four hours of blood collec- tion. Plasma viscosity was measured with a tube plasma viscometer (Plasmaviskosimeter KSPV4, Myrenne). Blood viscosity in $100 \mu \mathrm{m}$ tubes was calculated as the product of the measured plasma viscosity and the relative viscosity. Relative viscosity was derived from a previously published relative blood viscosity/haematocrit relationship for full term neonates. ${ }^{11}$ Red cell aggregation was assessed using the Myrenne Erythrocyte Aggregometer MA2, which consists of a transparent cone plate viscometer. ${ }^{12} \mathrm{~A}$ blood sample with an adjusted packed cell volume of 0.40 is sheared for 20 seconds to disperse all red cell aggregates. The drive motor is then stopped, and the light transmission increases with the time at a rate proportional to the rate of red cell aggregation (that is, at a rate proportional to the formation of cell free liquid gaps between aggregates). The increase in light transmission during a 20 second period is measured and displayed as an aggregation index.

The deformability of single red blood cells was observed and measured using a counterrotating, cone plate rheoscope (Effenberger, Munich), ${ }^{13}$ which was mounted on an inverted microscope (Leitz Diavert). ${ }^{14}$ Five shear stresses from 7 to $112 \mathrm{dyn} / \mathrm{cm}^{2}$ were applied, and the length and width of 40 red blood cells were measured in each sample at each shear stress. Red blood cell deformation was calculated as length minus width divided by length plus width. For the red cell deformability measurements, blood was diluted 1:50 (packed cell volume about 1\%) in phosphate buffered saline containing $350 \mathrm{~g} / 1$ of dextran 70 (Pharmacia), which has a mean (SD), osmolality of 295 (5) $\mathrm{mmol} / \mathrm{kg}$ and a viscosity of $35 \mathrm{mPa} /$ second at $25^{\circ} \mathrm{C}$.

\section{STATISTICAL ANALYSES}

The cardiovascular and haemorrheological variables studied on days 1 and 5 were compared with the Wilcoxon rank sum test for paired observations; a probability of less than 0.05 was accepted as significant. Regression analysis was used to make overall correlations among independent variables measured on days 1 and 5 .

\section{Results}

The cardiovascular variables are shown in table 1. Cardiac index, stroke volume, and blood pressure increased by $27 \%, 13 \%$, and $21 \%$, respectively, during the first five days after birth. Vascular resistance did not change. The haemorrheological variables are shown in table 2. Plasma viscosity, and total plasma protein and plasma fibrinogen concentrations increased significantly during the first five days by $12 \%$, $11 \%$, and $32 \%$, respectively. The increase in red

Table 1 Mean (SEM) changes in cardiovascular variables during the first five postnatal days

\begin{tabular}{llll}
\hline & Day l & Day 3 & Day 5 \\
\hline Cardiac output (ml/min/kg) & $151(10)$ & $180(12)$ & $192(12)^{*}$ \\
Stroke volume (ml) & $4 \cdot 6(0 \cdot 39)$ & $4 \cdot 6(0 \cdot 43)$ & $5 \cdot 2(0 \cdot 46)^{*}$ \\
Heart rate/min & $120(3)$ & $127(4)$ & $124(3)$ \\
Mean blood pressure (mm Hg) & $39(1 \cdot 1)$ & $44(3 \cdot 4)$ & $47(4 \cdot 7)^{*}$ \\
Resistance (mean blood pressure divided by cardiac output) & $258(17)$ & $244(25)$ & $244(12)$ \\
Vascular hindrance (resistance:blood viscosity) & $86(5 \cdot 6)$ & Not measured & $72(3 \cdot 5)^{*}$ \\
\hline
\end{tabular}


Table 2 Mean (SEM) changes in determinants of blood viscosity from day 1 to day 5

\begin{tabular}{|c|c|c|c|}
\hline & Day 1 & Day 5 & p Value \\
\hline $\begin{array}{l}\text { Packed cell volume } \\
\text { Total plasma protein (g/l) } \\
\text { Fibrinogen }(\mathrm{g} / \mathrm{l}) \\
\text { IgM (g/1) } \\
\boldsymbol{\alpha}_{2} \text {-Macroglobulin (g/l) } \\
\text { Plasma viscosity (mPa/s) } \\
\text { Erythrocyte deformability } \\
\text { shear stress: }\end{array}$ & $\begin{array}{l}0.49(0.1) \\
55(6) \\
2.13(0.3) \\
0.34(0.04) \\
5.47(1.5) \\
1.10(0.02)\end{array}$ & $\begin{array}{l}0.52(0.1) \\
61(8) \\
2.81(0.7) \\
0.4(0.05) \\
5.10(0.79) \\
1.23(0.03)\end{array}$ & $\begin{array}{l}>0.05 \\
<0.05 \\
<0.02 \\
<0.05 \\
>0.05 \\
<0.05\end{array}$ \\
\hline $\begin{array}{l}7 \mathrm{dyn} / \mathrm{cm}^{2} \\
28 \mathrm{dyn} / \mathrm{cm}^{2} \\
112 \mathrm{dyn} / \mathrm{cm}^{2} \\
\text { Erythrocyte aggregation } \\
\text { Calculated blood viscosity }(\mathrm{mPa} / \mathrm{s})\end{array}$ & $\begin{array}{l}0.35(0.03) \\
0.48(0.04) \\
0.57(0.03) \\
4.02(1.6) \\
3.00(0.30)\end{array}$ & $\begin{array}{l}0.35(0.02) \\
0.49(0.02) \\
0.58(0.004) \\
4.93(1.9) \\
3.39(0.69)\end{array}$ & $\begin{array}{l}>0.05 \\
>0.05 \\
>0.05 \\
>0.05 \\
<0.05\end{array}$ \\
\hline
\end{tabular}

cell aggregation was not significant $(\mathrm{p}<0 \cdot 10)$. Calculated whole blood viscosity increased between days 1 and 5 by $13 \%(p<\cdot 05)$. Vascular hindrance (calculated as the ratio of vascular resistance:blood viscosity) therefore decreased within the first five postnatal days by $16 \%$ $(\mathrm{p}<0.05)$. A decrease in vascular hindrance indicates vasodilation.

For correlation analysis the results of days 1 and 5 were combined. There were significant linear correlations between plasma fibrinogen concentration and plasma viscosity $(r=0.58$; $\mathrm{p}<0.001)$ and between plasma fibrinogen concentration and erythrocyte aggregation $(r=0.41$; $\mathrm{p}<0.05)$.

\section{Discussion}

In the present study cardiac output increased significantly during the first five postnatal days as a result of an increase in stroke volume. This increase in cardiac output $(27 \%$ between days 1 and 5) was nearly twice as high as the intraobserver variability for this method reported by others $^{15}$ and our group. ${ }^{10}$

Moreover, the increase in cardiac output was associated with an increase in blood pressure and indications of vasodilation. Only a few studies have been reported on the postnatal changes in cardiac output, and these have been done at different times. Mahoney et $\mathrm{al}^{3}$ and Wilson $e t \mathrm{al}^{16}$ measured aortic blood flow velocity with Doppler ultrasound and found an insignificant decrease in flow of $10 \%$ from day 1 to day 3. Alverson et al studied aortic blood flow velocity for the first time within the first four days after birth, then weekly until the age of 6 weeks, and every other month during the first year of life. ${ }^{4}$ They observed a nearly constant aortic blood flow velocity during the first year of life. As the aortic cross sectional area increased proportionally to body weight, cardiac output/kg varied little during the first year. During the first week of their study cardiac index increased by $8 \%$. Cord clamping times are not given in these reports.

Arcilla et al compared pulmonary and systemic blood flow changes (dye dilution) in neonates who had early or late cord clamping. ${ }^{5}$ On the first day neonates whose cords had been clamped late had a higher left ventricular output as a result of the higher blood volume, compared with those whose cords had been clamped early. Both groups had a decrease in systemic flow resistance of about $10 \%$ during the first 24 hours after birth. In the group whose cords had been clamped late, the left ventricular output/ $\mathrm{m}^{2}$ increased by about $4 \%$ between days 1 and 2 . In the present study cords were clamped 10 to 20 seconds after birth so that the infants probably received a placental transfusion of 10 to 20 $\mathrm{ml} / \mathbf{k g}^{17}$

Several papers have reported a steady increase in arterial blood pressure with increasing age and weight. ${ }^{2}$ We found similar increases in cardiac output and blood pressure during the first five postnatal days. Thus, the flow resistance (computed as ratio of blood pressure: cardiac output) remained unchanged. Flow resistance is often used as an indicator of vessel geometry, but in circular vessels it is the product of blood viscosity and vascular hindrance. Blood viscosity in vessels or tubes with rapid flow (for example, the aorta) increases as the plasma viscosity and packed cell volume increase and the red cell deformability decreases. Packed cell volume and red cell deformability remained unchanged during the first five days. As blood viscosity rises linearly with increasing plasma viscosity, blood viscosity probably increased by a percentage similar to plasma viscosity (table 2). Because the flow resistance remained constant during the first five days, vascular hindrance (computed as the ratio of blood flow resistance:blood viscosity) decreased by a similar extent as the blood viscosity rose (table 1). In other words, the increasing blood viscosity was compensated for by viscodilatation.

The rise in plasma viscosity during the first five postnatal days was related to the increase in plasma protein concentration. Plasma viscosity depends on the total plasma protein concentration but is more influenced by high molecular weight proteins like fibrinogen than by small proteins like albumin. Red cell aggregation is also principally caused by fibrinogen, which forms bridges between adjacent erythrocytes. ${ }^{12}$ The slight but not significant postnatal increase in red cell aggregation can also be explained by the increase in plasma fibrinogen concentration. Under physiological conditions erythrocyte aggregation takes place only in veins, where shear stresses are low. Strong red cell aggregation may impair venous return. Red cell aggregation in neonates is low compared with healthy adults. ${ }^{12}$ The $20 \%$ increase in red cell aggregation during the first five postnatal days probably did not affect cardiac output.

We conclude that in healthy, full term neon- 
ates cardiac output increases during the first five postnatal days, and this increase is associated with increasing arterial pressure and vasodilation. The potential negative effect of blood viscosity on cardiac output seems to be compensated for by vasodilation.

1 Lamport H. Hemodynamics. In: Fulton JF, ed. Textbook of 2 physiology. 17th Ed. Philadelphia: Saunders, 1955:595-9. Marx GF, Cabe CM, Kim YI, Eidelman AI.

3 Mahoney LT, Coryell KG, Lauer RM. The newborn transitional circulation: a two-dimensional Doppler echocardiographic study. F Am Coll Cardiol 1985;6:623-9.

4 Alverson DC, Aldrich M, Angelus P, Backstrom C, Werner $S$. Longitudinal trends in left ventricular cardiac output in healthy infants over the first year of life. $\mathcal{F}$ Ultrasound Med 1987;6:519-24.

5 Arcilla RA, Oh W, Wallgren G, Hanson J, Gessner I, Lind J. Quantitative studies of the human neonatal circulation. II. Hemodynamic findings in early and late clamping of the umbilical cord. Acta Paediatr Scand 1967;56(suppl 179): 23-42.

6 Lister G, Walter TK, Versomold HT, Dallman PR, Rudolph AM. Oxygen delivery in lambs: cardiovascular and hemaAM. Oxygen delivery in lambs: cardiovascular and hema-
tologic development. Am $f$ Physiol 1979;237:H668-75.

7 Teitel DF, Sidi D, Chin T, Brett C, Heymann MA, Rudolph
AM. Developmental changes in the myocardial contractile reserve in the lamb. Pediatr Res 1985;19:948-55.

8 Gruskin AB, Edelmann CM, Yuan S. Maturational changes in renal blood flow in piglets. Pediatr Res 1970;4:7-12.

9 Thomas WP, Madigan JE, Backus KQ, Powell WE. Systemic and pulmonary haemodynamics in normal neonatal foals. $f$ Reprod Fertil 1987;35:623-8.

10 Mandelbaum-Isken VH, Linderkamp O. Pulsed Doppler evaluation of cardiac output in neonates using the apical window. Pediatr Cardiol 1990(in press)

11 Linderkamp O, Meiselman HJ, Wu PY, Miller FC. Blood and plasma viscosity and optimal hematocrit in the normal and plasma viscosity and optimal hematocrit in the norma

2 Linderkamp O, Ozanne P, Wu PYK, Meiselman HJ. Red blood cell aggregation in preterm and term neonates and blood cell aggregation in preterm and

13 Schmid-Schönbein H, Volger E, Teitel P, Kiesewetter H, Dauer U, Heilmann L. New hemorheological techniques for the routine laboratory. Clinical Hemorheology 1982;2: 93-105.

14 Linkderkamp O, Günter M, Hiltl W, Vargas VM. Erythrocyte deformability in the fetus, preterm, and term neonate. Pediatr Res 1986;20:93-6.

15 Hudson I, Houston A, Aitchison T, Holland B, Turner T. Reproducibility of measurements of cardiac output in newborn infants by Doppler ultrasound. Arch Dis Child 1990;65:15-9.

16 Wilson N, Reed K, Allen HD, Marx GR, Goldberg SJ Doppler echocardiographic observations of pulmonary and transvalvular velocity changes after birth and during the transvalvular velocity changes after birth and during

17 Yao AC, Lind J. Placental transfusion. Am $\mathcal{F}$ Dis Child 1974; 127:128-41. 